\title{
ENERGIA METABOLIZÁVEL DE ALGUNS ALIMENTOS ENERGÉTICOS PARA FRANGOS DE CORTE, DETERMINADA POR ENSAIOS METABÓLICOS E POR EQUAÇÕES DE PREDIÇÃO ${ }^{1}$
}

\author{
Metabolizable energy of some energy foods for broilers, \\ determined by metabolic assays and prediction equations \\ Adriano Kaneo Nagata ${ }^{2}$, Paulo Borges Rodrigues, \\ Rilke Tadeu Fonseca de Freitas ${ }^{3}$, Antônio Gilberto Bertechini ${ }^{3}$, Elias Tadeu Fialho ${ }^{3}$
}

\begin{abstract}
RESUMO
Dois ensaios metabólicos com pintos em crescimento (método tradicional de coleta total de excretas) foram conduzidos no Departamento de Zootecnia da UFLA, Lavras - MG, para determinar a Energia Metabolizável Aparente corrigida (EMAn) de alguns alimentos, bem como a determinação dessa energia por equações de predição descritas na literatura nacional e estrangeira. No ensaio I, determinou-se a EMAn de alguns alimentos energéticos alternativos ao milho (gérmen de milho, quirera de milho, milheto moído e em grão e sorgo moído e em grão) e, em um segundo, a EMAn de sete híbridos de milho. Paralelamente aos experimentos, foram realizadas as análises laboratoriais para a determinação da composição centesimal dos alimentos testados, a qual foi usada na predição da EMAn pelas equações. Os valores calculados foram, então, comparados com os observados, utilizando-se a correlação de Spearman, teste de agrupamento SCOTT-KNOTT e intervalos de confiança (IC) a partir dos valores de EMAn obtidos nos ensaios metabólicos. A EMAn do milheto foi de 3223 e $3279 \mathrm{kcal} / \mathrm{kg}$ de MS para a amostra moída e em grão, respectivamente. O sorgo apresentou uma EMAn de 3529 e $3573 \mathrm{kcal} / \mathrm{kg}$ de MS, moído e em grão, respectivamente. A EMAn determinada para o gérmen de milho foi de $3503 \mathrm{kcal} / \mathrm{kg}$ de MS, enquanto, para a quirera de milho, foi de $3351 \mathrm{kcal} / \mathrm{kg}$ de MS. Os valores energéticos dos híbridos variaram de 3665 a $3804 \mathrm{kcal} / \mathrm{kg}$ de MS. Entre as equações estudadas, a equação 4021,8 $227,55 \mathrm{MM}$ foi a única que se correlacionou $(\mathrm{P}<0,01)$ com valor médio de EMAn observada in vivo, além de estimar o maior número de valores energéticos dentro do IC calculado. As demais equações não se correlacionaram $(\mathrm{P}<0,01)$ com os valores de EMAn. Diante dos resultados obtidos neste experimento, pode-se concluir que a equação 4021,8 - 227,55MM é a mais indicada para predizer valores de EMAn dos alimentos estudados.
\end{abstract}

Termos para indexação: Predição da energia, composição química, milho e subprodutos, milheto, sorgo.

\section{ABSTRACT}

Two metabolism assays were carried out with chicks in growth (traditional method of total collection of excreta) in the Animal Science Department of UFLA, Lavras - MG, to determinate of the nitrogen-corrected Apparent Metabolizable Energy (AMEn) of some feedstuffs, as well as the determination of the energy values by prediction equations presented in the national and international literature. In the assay I, it was determined AMEn of some energy alternative feedstuffs to the corn (corn germ, corn quirera, ground and grain millet and ground and grain sorghum) and, in the second, AMEn of the seven corn hybrids. At same time to the experiments, it were realized laboratory analyses for determination centesimal composition of the tested feedstuffs. The food composition it was used in the prediction AMEn by equations. The calculated values were, then, compared with observed, using the Spearman correlation and SCOTT-KNOTT test. In addition, confidence intervals were obtained by the metabolic assays. Ground millet AMEn was similar to AMEn grain millet (3223 and $3279 \mathrm{kcal} / \mathrm{kg}$ DM respectively), being the same observed for the sorghum (3529 and $3573 \mathrm{kcal} / \mathrm{kg}$ DM, ground and grain, respectively). The AMEn for the corn germ was $3503 \mathrm{kcal} / \mathrm{kg} \mathrm{DM}$, while, for the corn quirera, it was $3351 \mathrm{kcal} / \mathrm{kg} \mathrm{DM}$. The corn hybrids energy values varied from 3665 to 3804 $\mathrm{kcal} / \mathrm{kg}$ DM. Among the studied equations, the 4021.8 - 227.55ash equation only correlated $(\mathrm{P}<0,01)$ with AMEn mean value observed in vivo, estimating the largest number of energy values inside of calculated confidence intervals. The other equations were not correlated $(\mathrm{P}<0,01)$ with the AMEn values. The results obtained in this assays, allow concluded that the $4021.8-$ 227.55ash equation should be used to predict EMAn values of the studied feedstuffs.

Index terms: Prediction of the energy, chemical composition, corn and by-products, millet, sorghum.

(Recebido para publicação em 14 de abril de 2003 e aprovado em 7 de outubro de 2003)

\footnotetext{
1. Parte da dissertação de mestrado do primeiro autor - Projeto financiado pelo CNPq.

2. Zootecnista, Doutorando do Departamento de Zootecnia da Universidade Federal de Lavras/UFLA - Caixa Postal 37 - $37200-000$ - Lavras, MG.

3. Professores do DZO/UFLA.
} 


\section{INTRODUÇÃO}

Apesar do bom conhecimento dos alimentos normalmente utilizados na avicultura, sabe-se que existem variações nas composições dos mesmos, pois regiões geográficas, condições de plantio, fertilidade de solo, variabilidade genética dos cultivares, formas de armazenamento e processamento dos grãos vegetais, além da composição e forma de obtenção de produtos de origem animal, são fatores que influenciam nos valores nutricionais dos alimentos.

A determinação da composição química completa dos ingredientes utilizados na formulação é onerosa e impraticável por ser demorada e, muitas vezes, trabalhosa, levando ao constante uso de tabelas e matrizes de composição, determinadas em laboratórios (NRC, 1994). Segundo Silva (1978), na formulação de rações, a composição dos ingredientes e seus respectivos valores energéticos devem ser os mais exatos possíveis, justificando a determinação da composição química e dos valores de energia metabolizável dos alimentos nacionais comumente utilizados na formulação de rações de mínimo custo.

Albino et al. (1992) observaram que para se obter sucesso na formulação de rações para aves, um dos aspectos mais importantes é o conhecimento preciso do conteúdo energético dos alimentos, o que possibilita um fornecimento adequado de energia para as aves.

Os valores energéticos dos alimentos para aves podem ser determinados por vários métodos. Albino e Silva (1996) citam o método tradicional de coleta total de excretas (SIBBALD e SLINGER, 1963), o da alimentação precisa (SIBBALD, 1976) e o método rápido de Farrel (1978), destacando também o uso de equações de predição, as quais se baseiam na composição química dos alimentos.

Há vários anos, a possibilidade de se utilizarem equações para predizer os valores energéticos dos alimentos tem sido objetivo de pesquisas, ou seja, vários pesquisadores têm desenvolvido equações para estimar a energia metabolizável por meio de sua composição proximal (NRC, 1994). Janssen (1989) elaborou a Tabela Européia de Valores Energéticos de Alimentos para Aves, na qual apresenta uma série de equações de predição dos valores de EMAn para vários grupos de alimentos, fundamentado na composição química ou nos coeficientes de digestibilidade dos nutrientes (gordura, proteína bruta e extratos não nitrogenados), com dados oriundos de vários experimentos na Europa. O autor ressalta, entretanto, que para alimentos cuja composição química varia muito da média apresentada, as equações podem levar à predição de resultados diferentes.
Diante desse fato, objetivou-se com a presente pesquisa a determinação da Energia Metabolizável Aparente corrigida (EMAn) de híbridos de milho e subprodutos do milho, como gérmen e quirera, e amostras de milheto e sorgo com frangos de corte em crescimento e avaliar a viabilidade de utilização de algumas equações de predição, disponíveis na literatura, na determinação EMAn desses alimentos, comparando-as com os valores determinados em ensaios metabólicos com frangos de corte em crescimento.

\section{MATERIAL E MÉTODOS}

Dois ensaios metabólicos foram conduzidos no Setor de Avicultura do Departamento de Zootecnia - DZO da Universidade Federal de Lavras - UFLA, no período de junho a agosto. Inicialmente, as aves foram criadas em galpão de alvenaria até a idade de 16 dias, período no qual receberam uma ração inicial de frangos de corte, tendo como ingredientes básicos milho e farelo de soja, formulada de acordo com as recomendações de Rostagno et al. (2000), a qual foi utilizada como ração-referência no ensaio de metabolismo (Tabela 1). Após esse período, as aves foram pesadas e transferidas para uma sala com controle de temperatura, recebendo luz artificial por 24 horas. As aves foram distribuídas aleatoriamente nas gaiolas das baterias, onde receberam os alimentos a serem testados. Para determinação dos valores de energia metabolizável aparente corrigida (EMAn), pelo método tradicional de coleta total, do milheto (moído e em grão), sorgo (moído e em grão), gérmen de milho desengordurado e farelo de quirera de milho, foram utilizados 210 pintos machos da linhagem Cobb, com peso médio de $325 \mathrm{~g} \pm$ $5 \mathrm{~g}$, que receberam as rações experimentais com os seis alimentos e a ração-referência. Os alimentos substituíram a ração-referência em $40 \%$. Foi determinada EMAn de cada alimento testado e da ração-referência em seis repetições de cinco aves cada parcela. As rações e água foram fornecidas à vontade, por um período de dez dias, sendo sete dias de adaptação (pré-experimental) e três de coleta total de excretas em cada unidade experimental, a qual foi realizada uma vez ao dia, iniciada sempre às 8 horas da manhã. De acordo com os resultados de Martinez (2002), o período de coleta na determinação do valor energético foi reduzido de cinco para três dias nos dois experimentos.

Para determinação dos valores de EMAn de sete híbridos de milho, foram utilizados 240 pintos machos da linhagem Cobb, com um peso médio de $467 \mathrm{~g} \pm 4 \mathrm{~g}$ que receberam as rações experimentais com os sete híbridos e a ração-referência (Tabela 1), na qual os alimentos substituíram a ração-referência em $40 \%$. O pro- 
cedimento experimental adotado e as análises laboratoriais seguiram o descrito no ensaio metabólico I. Os valores de EMA dos dois ensaios foram determinados conforme as fórmulas de Matterson et al. (1965) e ajustados para a retenção de nitrogênio.

Com a composição química dos alimentos, foram obtidos os valores de EMAn a serem comparados com os valores de EMAn obtidos diretamente nos ensaios metabólicos. As equações de Rodrigues (2000) e Rodrigues et al. (2001) foram estimadas para alimentos do grupo do milho (milho e subprodutos) a partir da composição química e valores de EMAn do milho e de seus subprodutos, ou seja, cada equação pode ser utilizada para predizer os valores energéticos desse grupo de alimentos. No entanto, essas equações não foram descritas para predizer a EMAn do milheto e sorgo, sendo utilizadas no presente trabalho pelo fato de a composição química desses alimentos ser similar à do milho. Janssen (1989) cita equações em que cada alimento possui uma ou mais equações para estimar seu valor energético, conforme descritas na Tabela 1.

Para o farelo de quirera de milho, um subproduto da Empresa Caramuru Alimentos LTDA, não há uma equação específica na tabela de Janssen (1989) para predizer seu valor energético. Diante disso, utilizou-se a equação de predição descrita para o milho por apresentar maior proximidade com a composição química do farelo de quirera.

Correlações de Spearman, teste de agrupamento SCOTT-KNOTT e intervalos de confiança (IC) foram utilizados para verificar a aplicabilidade dessas equações. As análises estatísticas foram feitas pelo pacote computacional SAEG (UFV, 1992), considerando como tratamentos:

T1: Valores de EMAn dos ensaios metabólicos;

T2: Valores de EMAn estimados pela equação 1 de Rodrigues et al. (2001);

T3: Valores de EMAn estimados pela equação 2 de Rodrigues et al. (2001);

T4: Valores de EMAn estimados pela equação 3 de Rodrigues et al. (2001);

T5: Valores de EMAn estimados pela equação 4 de Rodrigues (2000);

T6: Valores de EMAn estimados pela equação 5 de Rodrigues et al. (2001);

T7: Valores de EMAn estimados pela equação 6 de Rodrigues (2000);

T8: Valores de EMAn estimados pela equação 7 de Rodrigues (2000);
T9: Valores de EMAn estimados pela equação 8 de Rodrigues (2000);

T10: Valores de EMAn estimados pelas equações de Janssen (1989).

TABELA 1 - Composição centesimal e calculada da ração referência.

\begin{tabular}{|c|c|}
\hline Ingredientes & $(\%)$ \\
\hline Milho & 58,000 \\
\hline Farelo de soja & 35,700 \\
\hline Óleo vegetal & 2,500 \\
\hline Fosfato bicálcico & 1,850 \\
\hline Calcário calcítico & 1,000 \\
\hline Sal & 0,400 \\
\hline DL-Metionina & 0,200 \\
\hline L-Lisina HCL & 0,100 \\
\hline Suplemento vitamínico $^{1}$ & 0,100 \\
\hline Suplemento mineral $^{2}$ & 0,100 \\
\hline Anticoccidiano & 0,050 \\
\hline Total & 100 \\
\hline \multicolumn{2}{|c|}{ Composição calculada } \\
\hline Energia metabolizável (kcal/kg) & 2970 \\
\hline Proteína bruta \% & 21,50 \\
\hline Metionina + cistina $\%$ & 0,90 \\
\hline Lisina $\%$ & 1,10 \\
\hline Cálcio \% & 0,90 \\
\hline Fósforo disponível \% & 0,42 \\
\hline Sódio \% & 0,20 \\
\hline
\end{tabular}

1/Conteúdo por kg do produto: Vit. A - 12.000.000

UI; Vit. $D_{3}$ - 2.200.000 UI; Vit E - 30.000 UI; Vit $B_{1}$ 2,2 g; Vit $B_{2}-6,0$ g; Vit $B_{6}-3,3$ g; Vit $B_{12}-0,016$ g; Ácido nicotínico - 53,0 g; Ác. Pantotênico - 13,0 g; Vit. $K_{3}$ - 2,5 g; Ác. Fólico -1,0 g; antioxidante - 120,0 g e veículo q.s.p. - $1000 \mathrm{~g}$.

2/Conteúdo por kg do produto: Manganês - 75 g; Ferro - 20 g; Zinco - 50 g; Cobre - 4 g; Cobalto - 0,2 g; Selênio - 0,25 g; Iodo - 1,5 g e veículo q.s.p. $-1.000 \mathrm{~g}$. 
Equações de predição de Rodrigues (2000) e Rodrigues et al. (2001)

Equação de predição 1(EQP-1)

Equação de predição 2(EQP-2)

Equação de predição 3(EQP-3)

Equação de predição 4(EQP-4)

Equação de predição 5(EQP-5)

Equação de predição 6(EQP-6)

Equação de predição 7(EQP-7)

Equação de predição 8(EQP-8)
4887,27 - 5,42PB - 32,74FDN - 127,52MM - 8,15Amido

$5167,33-8,62 \mathrm{~PB}-131,97 \mathrm{FB}-183,43 \mathrm{MM}$ - 14,71Amido

4466,32 - 33,51FDN - 109,11MM - 3,33Amido

4502,52 - 128,7FB - 161,81MM - 7,24Amido

$4281,55-39,97 \mathrm{FDN}-72,90 \mathrm{MM}$

$4337,27-55,17$ FDN

4453,34 - 253,84MM - 7,81Amido

$4021,8-227,55 \mathrm{MM}$

Equações de predição de Janssen (1989) $\rightarrow$ EQP-9

Equações de predição para o milheto

$36,21 \mathrm{~PB}+69,60 \mathrm{EE}+38,10 \mathrm{ENN}$

Equações de predição para o sorgo

$31,02 \mathrm{~PB}+77,03 \mathrm{EE}+37,67 \mathrm{ENN}$

Equações de predição para o gérmen

$21,12 \mathrm{~PB}+87,24 \mathrm{EE}+32,29 \mathrm{ENN}$

Equações de predição para a quirera

$36,21 \mathrm{~PB}+85,44 \mathrm{EE}+37,26 \mathrm{ENN}$

Equações de predição para o milho

$36,21 \mathrm{~PB}+85,44 \mathrm{EE}+37,26 \mathrm{ENN}$

\section{RESULTADOS E DISCUSSÃO}

\section{Composição centesimal dos alimentos}

Os alimentos apresentaram diferentes valores em suas composições químicas quando comparados às tabelas brasileiras (EMBRAPA, 1991; ROSTAGNO et al., 2000). A composição centesimal dos 13 alimentos testados encontram-se na Tabela 2. Essas diferenças, porém, eram esperadas, já que a fertilidade do solo, clima, genética, armazenamento e processamento, principalmente no caso de subprodutos, são fatores que interferem na composição química dos alimentos (ALBINO e SILVA, 1996; BUTOLO, 2002).

$\mathrm{O}$ milheto apresentou níveis superiores de $\mathrm{PB}$, EB e EE quando comparado ao milho. Esses teores foram, em média, 80,2, 1,5 e 29,4\%, respectivamente, superiores aos do milho. Rodrigues (2000) encontrou diferenças de 41,6, 2,5 e 116,0\% para os mesmos teores, respectivamente. Entretanto, em trabalhos realizados por Rostagno et al. (2000), a EB do milho foi 1,0\% superior à EB do milheto. O teor de proteína bruta do sorgo foi $35,5 \%$ superior ao do milho; no entanto, os teores de extrato etéreo e amido do milho foram 16,9 e 57,8\% maiores, respectivamente, aos teores do sorgo. Na tabela elaborada por Rostagno et al. (2000), essas comparações mostram-se bem diferentes; a PB do sorgo foi $3,1 \%$ superior à do milho, enquanto o EE e o amido do milho foram 22,2 e $3,7 \%$, respectivamente, superiores aos teores do sorgo.

Dos alimentos analisados, o farelo de gérmen apresentou o maior valor de energia bruta, possivelmente por apresentar também o maior valor em porcentagem de extrato etéreo. Além disso, apresentou composição química superior em quase todos os nutrientes analisados, quando comparado ao milho, com exceção do amido, o mesmo sendo observado por Rodrigues (2000).

Os híbridos de milho apresentaram diferenças, quando comparados entre si, em quase todos os nutrientes estudados $(6,1$ a $9,6 \% \mathrm{~PB} ; 3,8$ a $4,8 \% \mathrm{EE} ; 3860$ a $3991 \mathrm{kcal}$ de $\mathrm{EB} / \mathrm{kg}$ de $\mathrm{MN} ; 1,2$ a 2,1\% FB; 63,7 a $74,2 \%$ amido), estando de acordo com Soto-Salanova et al. (1996), que relatam diferenças nos teores de proteína, óleo e amido.

\section{Valores energéticos determinados em ensaio metabólico e estimados pelas equações de pre- dição}

Analisando os alimentos em conjunto, somente a equação 8 (4021,8 - 227,55MM) associou-se significativamente $(\mathrm{P}<0,01)$ com o valor médio de EMAn determinado no ensaio metabólico, sendo uma correlação positiva $(67,77 \%)$, confirmando a indicação de Rodrigues (2000). Os resultados das correlações de Spearman encontram-se na Tabela 3. Foi observado que à medida que diminuiu o número de variáveis consideradas no modelo de predição, os valores de EMAn calculados tornaram-se mais correlacionados com o valor médio determinado. Porém, Rodrigues (2000) e Nunes (2000) observaram que equações com duas a quatro variáveis predizem melhor os valores energéticos. 
TABELA 2 - Composição química e energética dos alimentos, expressos na matéria natural.

\begin{tabular}{|c|c|c|c|c|c|c|c|}
\hline \multirow{2}{*}{ Nutrientes } & \multicolumn{7}{|c|}{ Alimentos $^{1}$} \\
\hline & Milheto M & Milheto G & \multicolumn{2}{|l|}{ Sorgo M. } & Sorgo G. & Gérmen & Quirera \\
\hline $\operatorname{MS}(\%)$ & 88,71 & 88,71 & \multicolumn{2}{|l|}{88,90} & 88,90 & 89,59 & 89,52 \\
\hline $\mathrm{PB}(\%)$ & 14,23 & 14,23 & \multicolumn{2}{|l|}{10,73} & 10,73 & 10,77 & 8,46 \\
\hline $\mathrm{EB}(\mathrm{kcal} / \mathrm{kg})$ & 4063,2 & 4063,2 & \multicolumn{2}{|l|}{3920,5} & 3920,5 & 4318,2 & 3942,3 \\
\hline EMAn (kcal/kg) & 2859,1 & 2908,8 & \multicolumn{2}{|l|}{3137,4} & 3176,6 & 3138,4 & 2999,7 \\
\hline $\mathrm{EE}(\%)$ & 5,70 & 5,70 & \multicolumn{2}{|l|}{3,78} & 3,78 & 10,90 & 4,50 \\
\hline FDN (\%) & 16,26 & 16,26 & \multicolumn{2}{|l|}{14,20} & 14,20 & 18,50 & 16,99 \\
\hline FDA $(\%)$ & 5,15 & 5,15 & \multicolumn{2}{|l|}{5,73} & 5,73 & 4,99 & 4,67 \\
\hline FB (\%) & 1,64 & 1,64 & \multicolumn{2}{|l|}{1,59} & 1,59 & 3,65 & 3,81 \\
\hline ENN (\%) & 65,37 & 65,37 & \multicolumn{2}{|l|}{71,45} & 71,45 & 61,31 & 71,07 \\
\hline MM (\%) & 1,77 & 1,77 & \multicolumn{2}{|l|}{1,36} & 1,36 & 2,97 & 1,68 \\
\hline Amido (\%) & 60,80 & 60,80 & \multicolumn{2}{|l|}{43,97} & 43,97 & 52,81 & 57,78 \\
\hline $\mathrm{Ca}(\%)$ & 0,053 & 0,053 & \multicolumn{2}{|l|}{0,054} & 0,054 & 0,078 & 0,071 \\
\hline $\mathrm{P}(\%)$ & 0,17 & 0,17 & 0,31 & & 0,31 & 0,17 & 0,13 \\
\hline $\mathrm{Zn}(\mathrm{ppm})$ & 37,01 & 37,01 & 14,03 & & 14,03 & 32,42 & 17,63 \\
\hline $\mathrm{Cu}(\mathrm{ppm})$ & 15,46 & 15,46 & 7,15 & & 7,15 & 12,02 & 8,08 \\
\hline $\mathrm{Fe}(\mathrm{ppm})$ & 111,50 & 111,50 & 98,80 & & 98,80 & 65,88 & 208,70 \\
\hline Nutrientes & & & limentos (Híb & bridos c & de milho - HI & & \\
\hline vitinentes & HB-1 & HB-2 & HB-3 & HB-4 & HB-5 & HB-6 & HB-7 \\
\hline $\operatorname{MS}(\%)$ & 86,46 & 86,57 & 87,21 & 86,76 & 87,82 & 87,50 & 86,89 \\
\hline $\mathrm{PB}(\%)$ & 6,10 & 8,22 & 8,85 & 7,52 & 9,64 & 7,22 & 6,68 \\
\hline $\mathrm{EB}(\mathrm{kcal} / \mathrm{kg})$ & 3887,5 & 3932,8 & 3983,8 & 3945,1 & 3990,6 & 3895,1 & 3860,2 \\
\hline EMAn (kcal/kg) & 3193,7 & 3229,8 & 3317,4 & 3241,4 & 3319,5 & 3207,0 & 3209,5 \\
\hline $\mathrm{EE}(\%)$ & 4,36 & 4,53 & 4,05 & 4,50 & 4,77 & 4,28 & 3,78 \\
\hline FDN (\%) & 14,28 & 15,56 & 14,77 & 15,90 & 14,31 & 14,68 & 14,13 \\
\hline FDA $(\%)$ & 3,62 & 3,84 & 3,33 & 3,52 & 3,49 & 3,48 & 3,43 \\
\hline $\mathrm{FB}(\%)$ & 1,82 & 1,25 & 2,14 & 1,44 & 1,51 & 1,35 & 1,19 \\
\hline ENN (\%) & 72,81 & 71,24 & 71,02 & 72,02 & 70,55 & 73,28 & 74,15 \\
\hline MM (\%) & 1,37 & 1,32 & 1,15 & 1,28 & 1,34 & 1,38 & 1,08 \\
\hline Amido (\%) & 74,17 & 65,30 & 68,00 & 72,65 & 69,48 & 64,12 & 63,66 \\
\hline $\mathrm{Ca}(\%)$ & 0,037 & 0,033 & 0,034 & 0,031 & 0,042 & 0,048 & 0,046 \\
\hline $\mathrm{P}(\%)$ & 0,14 & 0,13 & 0,13 & 0,16 & 0,18 & 0,15 & 0,12 \\
\hline $\mathrm{Zn}(\mathrm{ppm})$ & 13,84 & 14,32 & 14,88 & 13,61 & 15,47 & 12,47 & 13,75 \\
\hline $\mathrm{Cu}(\mathrm{ppm})$ & 6,33 & 7,22 & 6,5 & 7,31 & 10,31 & 5,52 & 8,91 \\
\hline $\mathrm{Fe}(\mathrm{ppm})$ & 38,61 & 42,81 & 38,88 & 30,23 & 34,04 & 29,58 & 39,51 \\
\hline
\end{tabular}

${ }^{1}$ Milheto M. - milheto moído; Milheto G. - milheto em grão; Sorgo M. - sorgo moído; Sorgo G. - sorgo em grão; Gérmen - farelo de gérmen de milho; Quirera - farelo de quirera de milho. 
As equações $3(4466,32$ - 33,51FDN 109,11MM - 3,33AMIDO), 5 (4281,55 - 39,97FDN $72,90 \mathrm{MM})$ e $7(4453,34-253,84 \mathrm{MM}-7,81 \mathrm{AMIDO})$ mostraram-se altamente correlacionadas com a equação 8 (4021,8 - 227,55MM) (78,34; 77,24 e 74,48 \%), sendo a equação 5 (4453,34 - 253,84MM - 7,81AMIDO) correlacionada $(\mathrm{P}<0,05)$ com o valor médio determinado in vivo.

Além da correlação, realizou-se a comparação entre o valor médio da EMAn obtida in vivo com os valores médios de EMAn de cada equação de predição (Tabela 4), aplicando-se o teste de agrupamento SCOTT-KNOTT. Como era de se esperar, apenas a equação 8 (4021,8 - 227,55MM) assemelhou-se estatisticamente $(\mathrm{P}<0,05)$ ao ensaio metabólico, sendo a que melhor estimou os valores de EMAn dentro do intervalo de confiança de cada alimento, como pode ser visto mais adiante. $\mathrm{O}$ valor médio obtido pelas equações de Janssen (1989) foi o maior apresentado, superestimando, de modo geral, os valores energéticos, conforme verificado nas tabelas 4 e 5 . As demais equações subestimaram os valores de EMAn, quando comparado ao valor médio obtido nos ensaios metabólicos.

Para uma análise de forma separada, em relação aos alimentos, foram realizadas comparações entre o valor de EMAn de cada alimento, utilizando para isso os inter- valos de confiança (IC) determinados considerando as observações nos ensaios de metabolismo, com os valores de EMAn determinado por cada equação (Tabela 5).

As equações $1(4887,27-5,42 \mathrm{~PB}-32,74 \mathrm{FDN}-$ 127,52MM - 8,15 AMIDO), 4 (4502,52 - 128,7FB 161,81MM - 7,24 AMIDO) e 7 (4453,34 - 253,84MM 7,81AMIDO) estimaram apenas a EMAn de um alimento. Em todas essas equações, a MM e o amido participam de sua composição, sendo a primeira a equação com mais variáveis (PB, FDN, MM e amido). As equações que utilizaram a $\mathrm{PB}$ e a $\mathrm{FB}$ como variáveis independentes não se mostraram boas para predizer os valores de EMAn, no entanto, a FB apresentou correlação negativa de 91,9\% com os valores energéticos (Rodrigues, 2000).

As equações $3(4466,32$ - 33,51FDN $109,11 \mathrm{MM}$ - 3,33AMIDO) e 5 (4281,55 - 39,97FDN 72,9MM) estimaram a EMAn das amostras de sorgo e a EMAn do farelo de quirera. No entanto, ressalta-se que o referido autor não utilizou o milheto, o sorgo e o farelo de quirera na estimativa de suas equações.

Com resultado semelhante, a equação $6(4337,27$ - 55,17FDN) estimou o valor de EMAn dos milhetos, do sorgo moído e do farelo de quirera, utilizando como variável apenas a FDN, sendo essa a variável de maior correlação negativa $(0,9702 \%)$ com os valores energéticos, de acordo com Rodrigues (2000).

TABELA 3 - Correlações de Spearman entre a média dos valores de EMAn determinado (ensaio metabólico) com a média da EMAn estimada (equações de predição).

\begin{tabular}{llcccc}
\hline \multicolumn{1}{c}{ Variável } & Variável $^{\mathbf{1}}$ & Obser & Correlação & Z & Signif \\
\hline Ensaio Metabólico & Equação 1 & 13 & 0,1873 & 0,6489 & 0,2582 \\
Ensaio Metabólico & Equação 2 & 13 & $-0,0716$ & $-0,2481$ & 0,4020 \\
Ensaio Metabólico & Equação 3 & 13 & 0,4628 & 1,6032 & 0,0544 \\
Ensaio Metabólico & Equação 4 & 13 & 0,1653 & 0,5726 & 0,2835 \\
Ensaio Metabólico & Equação 5* & 13 & 0,4793 & 1,6605 & 0,0484 \\
Ensaio Metabólico & Equação 6 & 13 & 0,2920 & 1,0116 & 0,1559 \\
Ensaio Metabólico & Equação 7 & 13 & 0,2314 & 0,8016 & 0,2114 \\
Ensaio Metabólico & Equação 8** & 13 & 0,6777 & 2,3476 & 0,0094 \\
Ensaio Metabólico & Equação 9 & 13 & 0,3967 & 1,3742 & 0,0847 \\
\hline
\end{tabular}

${ }^{1}$ Equações 1, 2, 3, 4, 5, 6, 7 e 8, Rodrigues (2000) e Rodrigues et al. (2001); Equação 9, Janssen (1989);

** Correlação significativa $(\mathbf{P}<0,01)$ * Correlação significativa $(\mathbf{P}<0,05)$. 
A equação que estimou maior número de valores energéticos foi a equação 8, de Rodrigues (2000), que utilizou apenas a MM para estimar o valor de EMAn. Segundo o autor, a MM foi a variável que mais correlacionou-se com os valores energéticos, participando de quase todas as equações. Entretanto, Nunes (2000), trabalhando com trigo e alguns subprodutos, ressalta que a equação composta pela $\mathrm{PB}$ e FDN é a que melhor se ajusta à predição dos valores energéticos.

Em relação aos híbridos de milho, a equação 8 (4021,8 - 227,55MM) mostrou-se como a melhor equação, estimando seis dos sete híbridos testados, po- rém, as demais equações de Rodrigues (2000) e Rodrigues et al. (2001) não estimaram nenhum valor de EMAn dos híbridos.

Apesar de utilizar uma equação específica para cada alimento, as equações $21,12 \mathrm{~PB}+$ $87,24 \mathrm{EE}+32,29 \mathrm{ENN}$ e $36,21 \mathrm{~PB}+85,44 \mathrm{EE}+$ 37,26ENN de Janssen (1989) predisseram apenas dois valores energéticos: a EMAn do farelo de gérmen de milho e a EMAn do híbrido de milho 3, respectivamente, ficando fora dos intervalos de confiança os demais híbridos. Em todas as equações de Janssen (1989), o EE foi a variável de maior expressão.

TABELA 4 - Comparação entre os valores médios de EMAn dos alimentos obtidos pelo ensaio metabólico e pelas equações de Rodrigues (2000), Rodrigues et al. (2001) e de Janssen (1989).

\begin{tabular}{lc}
\hline \multicolumn{1}{c}{ Equações } & Médias $^{\mathbf{1}}$ \\
\hline EMAn $=$ Ensaio Metabólico & $3.582 \mathrm{~b}$ \\
EMAn $=4887,27-5,42 \mathrm{~PB}-32,74 \mathrm{FDN}-127,52 \mathrm{MM}-8,15$ Amido $=5167,33-8,62 \mathrm{~PB}-131,97 \mathrm{FB}-183,43 \mathrm{MM}-14,71$ Amido & $3.468 \mathrm{c}$ \\
EMAn $=4466,32-33,51 \mathrm{FDN}-109,11 \mathrm{MM}-3,33$ Amido & $3.449 \mathrm{c}$ \\
EMAn $=4502,52-128,7 \mathrm{FB}-161,81 \mathrm{MM}-7,24$ Amido & $3.460 \mathrm{c}$ \\
EMAn $=4281,55-39,97 \mathrm{FDN}-72,90 \mathrm{MM}$ & $3.442 \mathrm{c}$ \\
EMAn $=4337,27-55,17 \mathrm{FDN}$ & $3.457 \mathrm{c}$ \\
EMAn $=4453,34-253,84 \mathrm{MM}-7,81$ Amido & $3.373 \mathrm{c}$ \\
EMAn $=4021,8-227,55 \mathrm{MM}$ & $3.470 \mathrm{c}$ \\
EMAn $=$ Equações de Janssen $(1989)^{2}$ & $3.628 \mathrm{~b}$
\end{tabular}

${ }^{1}$ Médias seguidas de mesma letra não diferem estatisticamente $(P<0,05)$ pelo teste de agrupamento SCOTTKNOTT.

${ }^{2}$ Equação para milheto $=36,21 \mathrm{~PB}+69,60 \mathrm{EE}+38,10 \mathrm{ENN}$; Para sorgo $=31,02 \mathrm{~PB}+77,03 \mathrm{EE}+37,67 \mathrm{ENN}$; Para gérmen $=21,12 \mathrm{~PB}+$ 87,24EE + 2,29ENN; Para quirera = 21,12PB + 87,24EE + 32,29ENN; Para milho $=21,12 \mathrm{~PB}+87,24 \mathrm{EE}+32,29 \mathrm{ENN}$; 
TABELA 5 - Valores energéticos determinados, seus respectivos intervalos de confiança (IC), bem como os valores energéticos estimados pelas equações de predição de Rodrigues (2000), Rodrigues et al. (2001) e de Janssen (1989).

\begin{tabular}{|c|c|c|c|c|c|c|c|c|}
\hline Alimento & Milheto M & Milheto G & \multicolumn{2}{|c|}{ Sorgo M } & \multicolumn{2}{|c|}{ Sorgo G } & Gérmen & Quirera \\
\hline EMAn $^{2}$ & 3223 & 3279 & \multicolumn{2}{|c|}{3529} & \multicolumn{2}{|c|}{3573} & 3503 & 3351 \\
\hline IC & 3104 a 3342 & 3170 a 3388 & \multicolumn{2}{|c|}{3399 a 3659} & \multicolumn{2}{|c|}{3465 a 3681} & 3403 a 3603 & 3284 a 3418 \\
\hline $\mathrm{CV}^{3}$ & 3,5 & 3,2 & \multicolumn{2}{|c|}{3,5} & \multicolumn{2}{|c|}{2,9} & 2,7 & 1,9 \\
\hline EMAn1 & 3387 & \multicolumn{3}{|c|}{3701} & \multicolumn{2}{|c|}{3701} & 3243 & 3450 \\
\hline EMAn2 & 3410 & \multicolumn{3}{|c|}{3820} & \multicolumn{2}{|c|}{3820} & 3051 & 3231 \\
\hline EMAn3 & 3406 & \multicolumn{3}{|c|}{3600} & \multicolumn{2}{|c|}{3600} & 3216 & 3411 \\
\hline EMAn4 & 3445 & \multicolumn{3}{|c|}{3667} & \multicolumn{2}{|c|}{3667} & 3015 & 3184 \\
\hline EMAn5 & 3403 & \multicolumn{3}{|c|}{3532} & \multicolumn{2}{|c|}{3532} & 3214 & 3387 \\
\hline EMAn6 & 3326 & \multicolumn{3}{|c|}{3456} & \multicolumn{2}{|c|}{3456} & 3198 & 3290 \\
\hline EMAn7 & 3411 & \multicolumn{3}{|c|}{3680} & \multicolumn{2}{|c|}{3680} & 3151 & 3474 \\
\hline EMAn8 & 3567 & \multicolumn{3}{|c|}{3674} & \multicolumn{2}{|c|}{3674} & 3267 & 3596 \\
\hline EMAn9 & 3835 & \multicolumn{3}{|c|}{3729} & \multicolumn{2}{|c|}{3729} & 3524 & 3730 \\
\hline Alimento & HB-1 & HB-2 & HB-3 & & & HB-5 & HB-6 & HB-7 \\
\hline EMAn & 3694 & 3731 & 3804 & & & 3780 & 3665 & 3694 \\
\hline IC & 3604 a 3784 & 3645 a 3817 & 3700 a 3908 & 3648 & 3824 & 3716 a 3844 & 3623 a 3707 & 3631 a 3757 \\
\hline $\mathrm{CV}$ & 2,3 & 2,2 & 2,6 & & & 1,6 & 1,1 & 1,6 \\
\hline EMAn1 & 3420 & 3438 & 3475 & & & 3454 & 3495 & 3557 \\
\hline EMAn2 & 3300 & 3505 & 3368 & & & 3401 & 3526 & 3615 \\
\hline EMAn3 & 3460 & 3446 & 3496 & & & 3490 & 3488 & 3542 \\
\hline EMAn4 & 3366 & 3523 & 3410 & & & 3460 & 3519 & 3595 \\
\hline EMAn5 & 3506 & 3452 & 3509 & & & 3519 & 3496 & 3541 \\
\hline EMAn6 & 3426 & 3346 & 3403 & & & 3438 & 3412 & 3440 \\
\hline EMAn7 & 3394 & 3476 & 3511 & & 29 & 3447 & 3481 & 3566 \\
\hline EMAn8 & 3661 & 3674 & 3723 & & 85 & 3673 & 3664 & 3739 \\
\hline EMAn9 & 3824 & 3857 & 3799 & & 50 & 3855 & 3837 & 3830 \\
\hline
\end{tabular}

${ }^{1}$ Valor energético em itálico está dentro do intervalo de confiança;

${ }^{2}$ Valores energéticos expressos em kcal/kg de MS; EMAn-1 a 8 - equações de Rodrigues (2000) e Rodrigues et al. (2001); EMAn-9 - equações de Janssen (1989);

${ }^{3}$ Coeficiente de variação dos IC. 


\section{CONCLUSÕES}

A EMAn do milheto foi de 3223 e 3279 $\mathrm{kcal} / \mathrm{kg}$ de MN para a amostra moída e em grão, respectivamente. O sorgo apresentou uma EMAn de 3529 e $3573 \mathrm{kcal} / \mathrm{kg}$ de MN, moído e em grão, respectivamente. A EMAn determinada para o gérmen de milho foi de $3503 \mathrm{kcal} / \mathrm{kg}$ de $\mathrm{MN}$, enquanto, para a quirera de milho, foi de $3351 \mathrm{kcal} / \mathrm{kg}$ de MN. Os valores energéticos dos híbridos variaram de 3665 a $3804 \mathrm{kcal} / \mathrm{kg}$ de MN.

Diante dos resultados obtidos neste experimento, pode-se concluir que a equação 4021,8 227,55MM é a mais indicada para predizer valores de EMAn dos alimentos estudados. As equações de Janssen (1989), de maneira geral, superestimam os valores energéticos, enquanto as demais subestimam.

\section{REFERÊNCIAS BIBLIOGRÁFICAS}

ALBINO, L. F. T.; ROSTAGNO, H. S.; FONSECA, J. B.; TORRES, R. A. Utilização de diferentes sistemas de avaliação energéticas dos alimentos na formulação de rações para frangos de corte. Revista da Sociedade Brasileira de Zootecnia, Viçosa, v. 21, n. 6, p. 1037 1046, nov./dez. 1992.

ALBINO, L. F. T.; SILVA, M. A. Valores nutritivos de alimentos para aves e suínos determinados no Brasil. In: SIMPÓSIO INTERNACIONAL SOBRE EXIGÊNCIAS NUTRICIONAIS DE AVES E SUÍNOS, 1996, Viçosa. Anais... Viçosa: UFV, 1996. p. 303-318.

BUTOLO, J. E. Qualidade de ingredientes na alimentação animal. Campinas: [s.n.], 2002. 430 p.

EMPRESA BRASILEIRA DE PESQUISA AGROPECUÁRIA. Centro Nacional de Pesquisa de Suínos e Aves. Tabela de composição química e valores energéticos de alimentos para suínos e aves. 3. ed. Concórdia, 1991. 97 p. (EMBRAPA-CNPSA. Documentos, 19).

FARREL, D. J. Rapid determination of metabolizable energy of foods using cockrels. British Poultry Science, Edinburgh, v. 19, n. 3, p. 303-308, May 1978.

JANSSEN, W. M. M. A. European table of energy values for poultry feedstuffs. 3. ed. Beekbergen: [s.n.],
1989. 84 p. Spelderholt Center for Poultry Research and Information Services.

MARTINEZ, R. S. Avaliação da metodologia e do período de coleta na determinação do valor energético de rações para aves. 2002. 41 p. Dissertação (Mestrado) - Universidade Federal de Lavras, Lavras, 2002.

MATTERSON, L. D.; POTTER, L. M.; STUTZ, M. W.; SINGSEN, E. P. The metabolizable energy of feed ingredients for chickens. Connecticut: The University of Connecticut, 1965. 11 p. (Research Report, 7).

NATIONAL RESEARCH COUNCIL. Nutrient requirements of poultry. 9. ed. Washington: National Academy, 1994. 155 p.

NUNES, R. V. Valores energéticos e de aminoácidos digestíveis de grão de trigo e seus subprodutos para aves. 2000. 71 f. Dissertação (Mestrado em Zootecnia) - Universidade Federal de Viçosa, Viçosa, 2000 .

RODRIGUES, P. B. Digestibilidade de nutrientes e valores energéticos de alguns alimentos para aves. 2000. 204 f. Tese (Doutorado em Zootecnia) - Universidade Federal de Viçosa, Viçosa, 2000.

RODRIGUES, P. B.; ROSTAGNO, H. S.; ALBINO, L. F. T.; GOMES, P. C.; BARBOZA, W. A.; SANTANA, R. T. Valores energéticos do milheto, do milho e subprodutos do milho, determinados com frangos de corte e galos adultos. Revista da Sociedade Brasileira de Zootecnia, Viçosa, v. 30, n. 6, p. 1767-1778, nov./dez. 2001.

ROSTAGNO, H. S.; ALBINO, L. F. T.; DONZELE, J. L.; GOMES, P. C.; FERREIRA, A. S.; OLIVEIRA, R. F.; LOPES, D. C. Tabelas brasileiras para aves e suínos: composição de alimentos e exigências nutricionais. Viçosa: UFV/Departamento de Zootecnia, 2000. 141 p.

SIBBALD, I. R. A bioassay for true metabolizable energy in feedingstuffs. Poultry Science, Champaign, v. 55, n. 1, p. 303-308, Jan. 1976.

SIBBALD, I. R.; SLINGER, S. J. A biological assay for metabolizable energy in poultry feed ingredients together with findings which demonstrate some of the problems 
associated with evaluation of fats. Poultry Science, Champaign, v. 42, n. 1, p. 13-25, Jan. 1963.

SILVA, J. M. F. Composição química e energia metabolizável de ingredientes usados na alimentação de poedeiras e sua utilização em rações de mínimo custo. 1978. 53 f. Dissertação (Mestrado em Zootecnia) - Universidade Federal de Viçosa, Viçosa, 1978.
SOTO-SALANOVA, M. F.; GARCIA, O.; GRAHAM, H.; PACK, M. Uso de enzimas em dietas de milho e soja para frangos de corte. In: CONFERÊNCIA APINCO 96 DE CIÊNCIA E TECNOLOGIA AVÍCOLAS, 1996, Curitiba. Anais... Campinas: FACTA, 1996. p. 71-76.

UNIVERSIDADE FEDERAL DE VIÇOSA. Sistemas de análises estatísticas e genéticas. Versão 5.0. Viçosa, 1992. 59 p. Manual do usuário. 